\title{
Quantifiers and Intervention Effects:
}

\section{An Experimental Investigation}

$\mathrm{Min} \mathrm{Jegal}^{+}$

Kyungpook National University

\begin{abstract}
This study investigates why some quantifiers incur intervention effects while others do not at LF. Based on the understanding that controversial acceptability judgments of the relevant sentences make it difficult to precisely distinguish interveners from non-interveners, this study tests Korean intervention constructions via a formal experimentation. With reliable data from the experiment, I argue that an intervening factor is linked to the epistemic "non-specific" property and there is no absolute set of intervening quantifiers. The intervening status of a quantifier can be "off" when the addressee perceives it as a particular individual by context or real-world knowledge. This novel perspective provides a more convincing and unified account of the intervention phenomenon and its gradience in acceptability than previous studies in which the effect of "context" is ignored or underestimated.
\end{abstract}

Keywords: intervention effects, quantifiers, scrambling, embedding, D-linking, specificity

\section{Introduction}

The Intervention effect has been a major topic of research over the last few decades. It is observed in the overt and covert syntax; of the two, the 'LF-intervention effect' is the phenomenon in which the interpretation of a wh-in situ is disturbed by negation, focusing items or certain quantificational elements (Beck, 1996; Beck, 2006; Beck \& Kim, 1997; Erlewine \& Kotek, 2017; Kim, 2018; Tomioka, 2007). ${ }^{1)}$ Among those potential interveners, focusing elements are a stable set of interveners crosslinguistically, whereas the sets of 'intervening quantifiers' are inconsistent among languages. To illustrate, focusing items like only, even, and also serve as

* This work was supported by the Ministry of Education of the Republic of Korea and the National Research Foundation of Korea (NRF-2019S1A5B5A07112146).

† Corresponding author: 177117now@gmail.com

1) The phenomenon differs from the 'intervention effect' observed in the overt syntax in which a wh-movement is blocked in terms of Superiority (Chomsky, 1973) or Relativized Minimality (Rizzi, 1990; Rizzi, 2013). 
interveners in a great number of languages (e.g., German, Hindi, Japanese, Korean, Malayalam, Mandarin, etc.). By contrast, there have been substantial crosslinguistic variations in a set of quantificational interveners; for instance, in English and German, quantified expressions generally cause an intervention effect whereas, in Japanese and Korean, "certain" quantifiers such as 'everyone' and 'someone' have been considered as interveners. Most of previous studies have mainly dealt with focus-related interveners and not addressed intervening quantifiers extensively and in depth. For this reason, this paper focuses on 'quantifiers and their intervention effects' and attempts to investigate what property of an intervening quantifier blocks the interpretation of a wh-phrase in Korean, a wh-in situ language. I believe that although this study is performed within one language, its findings would extend to other languages and thereby provide a clue of understanding intervention effects as a widespread/universal phenomenon. Let us discuss details with the examples illustrated below.

(1) ?? Nwukwuna-ka enu kyoswu-lul conkyengha-ni? everyone-Nom which professor-Acc respect-Q 'Which professor does everyone respect?'

(Beck \& Kim, 1997)

(2) ?? Nwukwunka-ka mwuesul ilk-ess-ni? someone-Nom what-Acc read-Past-Q 'What did someone read?' (Tomioka, 2007)

$\begin{array}{clll}\text { Taypwupwun-uy } & \text { haksayng-tul-i } & \text { nwukwu-lul } & \text { conkyengha-ni? } \\ \text { most-Gen } & \text { student-PL-Nom } & \text { who-Acc } & \begin{array}{l}\text { respect-Q } \\ \text { 'Who do most students like? }\end{array} \\ & & \text { (Beck \& Kim, 1997) }\end{array}$

In (1) and (2), when the quantifier nwukwuna 'everyone' or nwukwunka 'someone' sits above the $w h$-word, it interferes with the interpretation of the wh-phrase; hence, their acceptabilities are rather infelicitous. In contrast, (3) shows that although the quantifier taypwupwun 'most' is placed higher than the wh-phrase, the sentence is interpretable. This paper questions why "certain" quantificational elements show intervention effects and others do not. Given that quantifiers are not referential elements, we can easily predict that they are not appropriate subjects in wh-questions. Nevertheless, some quantifiers are relatively acceptable but other quantifiers are not. What does this difference result from? 
To answer this question, distinguishing non-interveners from interveners must be preceded; however, drawing a precise distinction is not easy because the variability of grammatical judgments among native speakers is vast. Let us examine one of the examples that show the different acceptability judgments among previous researchers (e.g., Choi, 2007 vs. Kim, 2018).

(4) Sey salam isang-i colep phathi-ey mwues-ul ipko wa-ss-ni? three person more-Nom graduation party-at what-acc wear come-Past-Q 'What did more than three people wear in the graduation party?'

(Kim, 2018)

Kim (2018) categorizes 'numeral'-isang as a non-intervener while Choi (2007) contends that the same quantifier belongs to a group of interveners. Instead of admitting that there can be different judgments, we should at least examine why there is a disagreement. We need to investigate if the acceptability judgments on examples we use are reliable or not before proposing a new theory. This paper first attempts to secure reliable data by performing formal acceptability experiments and then explores the attributes of interveners'.2)

As for the experimental method, this study uses a hybrid experimental approach in which quantitative and qualitative research are combined. To be specific, the data of 85 people were collected for the experiment (quantitative) and the participants were instructed to write their thoughts/opinions about the reason why they gave scores of 3 points or lower (on a 7-point Likert scale) to a certain sentence (qualitative). Based on the empirical evidence from the formal experiment, I argue against the view that intervention effects can be understood in terms of the dichotomous distinction between interveners and non-interveners. Instead, we show the two non-trivial findings: first, there is not a fixed set of intervening quantifiers. Second, 'epistemic non-specificity' (Farkas, 1994) leads to intervention effects. More concretely, if the addressee recognizes a quantifier (the subject of a wh-question) as epistemically non-specific, the sentence is judged to be unacceptable. On the other hand, it will not serve as an intervener if it is perceived as a specific individual. The new perspective that an identical quantifier may or may not serve as an intervener not only gives important clues to understanding the intervention phenomenon but also accounts for why researchers/native speakers have given

2) In the literature, there has been no experimental study to this topic, "intervening quantifiers". 
distinct acceptability judgments.

The rest of this paper is structured as follows. Section 2 first points out that a dichotomous view of interveners and non-interveners is problematic; then, it introduces three kinds of specificity and argues that epistemic specificity is the most appropriate notion to account for intervention effects. Also, it shows that previous studies on three cancellation effects of intervention (scrambling, embedding and D-linking effects) have some limitations. Section 3 presents my experimental purposes, methods, results and discussion. Section 4 emphasizes that the perspective of the addressee is vital when the interpretation of a wh-question (an interrogative sentence) is evaluated, which is based on Tenny's (2006) speech act structure. Then I put forth the argument that an identical quantifier can be interpreted as 'non-specific' or 'specific' in every language. Lastly it is presented that focus-related intervention effects fall under a new framework this paper proposes for quantifier-related intervention effects. Section 5 concludes this paper.

\section{Background}

\subsection{Interveners vs. non-interveners}

Some quantifiers cannot be placed prior to a wh-phrase but others can. We will see in this section which quantifiers have been categorized as (non-) interveners in previous studies. Motu 'everyone/all', motun 'every/all', manhun 'many', and taypwupwun 'most' have been treated as non-interveners. Two kinds of examples among them are given below.

(5) a.

a. Motu-ka colep pathi-ey mues-ul ipko wa-ss-ni?3)
everyone-Nom graduation party-at what-Acc wear come-Past-Q
'What did everyone wear in the graduation party?'
b. Taypupun haksaying-tul-i colep pathi-ey mues-ul ipko
most student-PL-Nom graduation party-at what-Acc wear
wa-ss-ni?
come-Past-Q?

3) Kim (2018) used -no, the wh-question marker of Kyungsang Korean which has distinctive markers for a y/n-question and a wh-question. This paper uses '-ni' and '-e', question markers of standard Korean. 
What did most students wear at the graduation party?

The acceptabilities of (5) result from the successful interpretations of the wh-in situ phrases. Specifically, (5a) yields two kinds of interpretations: a collective and distributive reading. It can have answers like 'everyone came wearing a suit.' or 'Ann came wearing a dress, Ben, a suit, and Chris came with jeans.' (5b) allows only a collective interpretation. Whether its reading is collective or distributive, the availability of a wh-interpretation induces the acceptability of the sentence.

On the contrary, when nwukwuna 'everyone' or nwukwunka 'someone' occupies a higher position than a wh-word, the wh-question seems to be uninterpretable.

(6) a. ?? Nwukwuna-ka mwues-ul ilk-ess-ni? everyone-Nom what-Acc read-Past-Q 'What did everyone read?'

b. ?? Nwukwunka-ka mwuesul ilk-ess-ni? someone-Nom what-Acc read-Past-Q 'What did someone read?'

It has been argued that the two quantifiers, 'everyone' and 'someone' incur intervention effects. ${ }^{4)}$ Before moving to examples that have divergent acceptability judgments, let us discuss the attribute that separates interveners and non-interveners. Tomioka (2007) found, using Japanese and Korean examples, that intervening items share the property of not being topic-marked, which are referred to as Anti-Topic Items (ATIs). This paper does not deny the fact that interveners (focus-related elements and some quantifiers) have topic-resistant properties in common. However, he only deals with 'everyone' and 'someone' among quantifiers in his study; we need to test a wide range of quantifiers. For instance, numeral quantifiers in Korean can be topic-marked as in (7a) but do not appear to be free from an intervention effect as in (7b). That is, the availability of topic-marking is not directly linked to the absence of an intervention effect.

4) Researchers before Tomioka (2007) (Beck, 1996; Beck, 2006; Beck \& Kim, 1997; Kim, 2002 among others) had not paid much attention on the existential quantifier 'someone'; they mainly focused on negation, NPIs, focusing elements and 'every' among quantifiers. Even one of the recent studies, Kim (2018) does not include 'someone' when classifying Korean interveners. 
(7) a. Twu myeng-un kukes-ul ilk-ess-ta.

two CL-Top it-Acc read-past-Dec.

'Two people read it.'

b. ?? Twu myeng-i mwues-ul ilk-ess-e?

two CL-Nom what-Acc read-past-Q

'What did two people read?'

Although I regard (7b) as unacceptable, examples like (7b) have been contentious when it comes to acceptability judgments, which will be discussed with more details in the next example. For this reason, this paper performed an experimental study and its result shows that the mean acceptability of the sentences that contain numeral quantifiers like (7b) is about 3.5 on a 7-point Likert scale (this will be shown in section 3.3.1). Tomioka's analysis in terms of the correlation between an anti-topic trait and an intervening property is inadequate to cover this kind of example.

Let us observe more examples that are controversial in acceptability judgments.

(8) a. $\sqrt{ } /$ ?? Sey-myeng-i nwukwu-lul cohaha-ni?

three CL-Nom who-Acc like-Q

'Who do three (people) like?'

b. $\sqrt{ } / *$ Ney-myeng isang-i nwukwu-lul cohaha-ni?

four CL more-Nom who-Acc like-Q

'Who do more than four (people) like?'

c. * Tases-myeng miman-i nwukwu-lul cohaha-ni?

five CL fewer-Nom who-Acc like-Q

'Who do fewer than five (people) like?'

Kim (2018) categorizes numeral quantifiers presented in (8a) as non-interveners but I do not agree with her. She explained about the acceptability of (8a) that 'three' can be interpreted as an entity (a group), an <e> type obtained by type-shifting, and thus does not induce intervention effects. However, she did not take into consideration the possibility of non-specific interpretation of "a group of three". I point out that there are two possible interpretations (two possible acceptability judgments) for (8a). First, if sey-myeng 'three (people)' is interpreted as non-specific (i.e. we cannot recognize which group of people "three" are), the sentence is uninterpretable.5) In this case, 'three' cannot be convertible to <e> type, unlike her 
argument. On the other hand, when it is recognized as specific individuals, the question is acceptable. Whether or not a quantified subject is perceived as specific within the context should be reflected in determining intervention effects, which will be shown with our experimental evidence in section 3. Meanwhile, as for (8b), there is a conflict of grammaticality judgments between Choi (2007) and Kim (2018). Choi (2007) argues that -isang and -miman given in (8c) are interveners, whereas Kim (2018) treats -isang as a non-intervener and does not include -miman in her research.

As discussed above, the rigid distinction of a set of interveners and that of non-interveners is problematic and I claim that the intervening status of a quantificational item is changeable instead of being absolute. To be specific, the availability of the twofold interpretation (specific/ non-specific) of the quantifier in (8a) is reliant on the "knowledge" of people who judge its acceptability. The knowledge is about whether the interlocutor perceives it as a particular individual or not within a context.6) Adopting the notion of 'epistemic specificity', I maintain that intervention effects arise when a quantificational item is perceived as epistemically non-specific. The point is that an identical quantifier can be judged as either an intervener or not in accordance with the presence/absence of its epistemic specificity. Let us hypothesize that there are two situations; one is the context in which a quantifier is easily recognized as specific and the other context is the situation in which a quantifier has the possibility of being interpreted as non-specific. In this condition, we predict that participants will give better grades to the former than the latter. Later in section 3, an experimental result showing the effect of context will be presented. Before that, we will deal with more of the background issues; the notion of 'specificity' and amelioration effects.

\subsection{Specificity}

Specificity is a crucial notion in this study involved in the syntax-semantics

5) Comparing ku sey myeng 'the three' and sey myeng 'three', we can more easily understand the availability of non-specific reading of 'three'.

6) I point out that most researchers tend not to provide a context to participants (i.e., giving a sentence and asking them to judge) when testing acceptability judgments, especially with informal methods. Unless a certain context is provided, the participant creates "their own context" in which they determine the 'specificity status (specific/non-specific)' of a quantificational element. As in (8a), some judge the quantifier 'three' as 'a specific group of three people' in their context (knowledge world) while others say 'I don't know which people the 'three' refer to' in their context (knowledge world). Accordingly, experimental settings without providing contexts can contribute to a variance in judgments. 
interface and thus is required to be well-defined. According to Farkas (1994), there are three types of specificity: scopal specificity, epistemic specificity, and partitive specificity. She argues that they are independent and should be distinguished; I agree with and adopt her arguments and claim that 'epistemic specificity' is the most appropriate notion that can account for intervention effects among the three notions of specificity. Let us examine the characteristics of the three types of specificity first.

Scopal specificity:

(9) a. John wants to marry a Norwegian.

(a Norwegian $>$ want, want $>$ a Norwegian)

b. He met her last year.

c. He'll move to Norway to try to achieve this goal.

(Farkas, 1994)

Epistemic specificity (Fordor \& Sag (1982)):

(10) a. A student in Syntax 1 cheated on the exam.

b. His name is John.

c. We are all trying to figure out who it was.

(Farkas, 1994)

Partitive specificity (Enç (1991), Diesing (1992)):

(11) a. Several children entered the museum.

b. I saw two boys at the movies.

(Enç, 1991)

When the interpretation of an indefinite is dependent on some scope bearing elements (e.g. some quantifier or intensional predicate), the indefinite is 'scopally non-specific', and it is 'scopally specific' otherwise. The ambiguity of (9a) can be understood in these two ways. The continuation in (9b) forces a 'scopally specific' reading in which the indefinite has wide scope over the intensional predicate 'want', whereas the continuation in (9c) is associated with a 'scopally non-specific' reading in which the indefinite has the narrower scope. However, the ambiguity of examples like (10a) is not obtainable in terms of 'scopal specificity'. The sentence in (10a) allows two interpretations although there is no operator or quantifier that can participate in scopal relations. The continuation in (10b) forces an 'epistemically specific' interpretation of the indefinite; the speaker has an intended referent in mind, i.e., knows who the cheater is. On the other hand, in the reading of $(10 a)$ forced by the continuation in (10c), the indefinite is 'epistemically 
non-specific' - it does not denote a particular referent. Moreover, scopally 'non-specific' items can be interpreted as epistemically 'specific' as exemplified below.

(12) John believes that a unicorn has destroyed his flowerbeds. (believe $>$ a unicorn)

In this sentence, the indefinite a unicorn is 'scopally non-specific' as it has a narrow scope over believe and yet it is 'epistemically specific' since the speaker has an intended referent for it in mind. Given cases like (10) and (12), scopal and epistemic specificity should be kept apart.

Besides, the notion of partitive specificity is discrepant from the two types of specificity. Enç (1991) maintains that specific NPs do not always have wide scope (independent of scope relations) and partitives are necessarily specific. When an NP denotes a member of a familiar discourse set, it is taken to be partitive. In (11), the referent of 'two boys' is included in the referent of several children and thus the NP 'two boys' is said to be specific. However, as Farkas (1994) points out, partitives can be either 'epistemically non-specific' or 'scopally non-specific'.

(13) a. John wants to marry one of Steve's sisters. (He doesn't care which).

b. One of Steve's sisters cheated on the exam. (We have to find out which.)

(Farkas, 1994)

(13a) and (13b) shows that the partitive one of Steve's sisters can be interpreted as 'scopally non-specific' or 'epistemically non-specific'. To illustrate, in (13a) the partitive has narrow scope over the predicate want (scopally non-specific) and in (13b), it has no particular referent in the discourse (epistemically non-specific). Partitivity is independent of both scopal and epistemic specificity.

We have seen that the three types of specificity are discrete categories and now we will see epistemic specificity is the most proper notion to analyze intervention contexts. Erlewine \& Kotek (2017) hold the view that intervention correlates with scope-taking (in Japanese examples). According to them, scope-rigid quantifiers, i.e., scopally specific quantifiers, above a $w$ h-in situ phrase provoke intervention, whereas quantifiers that allow reconstruction below a wh-phrase and have scope ambiguities do not. 
(14) wh-mo universal quantifier is scope-rigid; subete is not:
a. Da're-mo-ga ko-nak-atta.
$\sqrt{\text { every }}>$ not, ${ }^{*}$ not $>$ every who-mo-Nom come-neg-past
'Everyone didn't come.'
b. [Subete-no mondai]-o toka-nak-atta. $\quad \sqrt{\text { every }}>$ not, $\sqrt{\text { not }}>$ every all-Gen problem-Acc solve-neg-past 'pro did not solve every problem.'
(Mogi, 2000)

(15) wh-mo is an intervener; subete is not:
a. ?? Da're-mo-ga nani-o
who-mo-Nom what-Acc
'What did everyone buy?'
kai-mashi-ta-ka?
buy-polite-past-Q

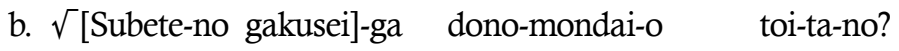 all-Gen student-Nom which-problem-Acc solve-past-Q 'Which problem(s) did every student solve?'

The quantifier 'everyone' showing a scope-rigidity in (14a) yields a marginal sentence as a consequence of an intervention effect as in (15a). On the other hand, (14b) shows that the quantificational elements 'all'-NPs can have a narrow scope reading in which it is interpreted below the negation. In this type of reading, the quantifier does not induce intervention as in (15b). However, this analysis does not extend to Korean examples. Though the quantifier taypwupwun 'most' is a scoperigid quantifier, it does not block the interpretation of a wh-in situ. Let us examine (16) and (17).

(16) has only one interpretation in which 'most' has a wider scope than the negation. The quantifier is scope-rigid and anticipates serving as an intervener; however, it is not born out as given below. 
(17) a. Taypwupwun-uy haksayng-tul-i enu kyoswu-lul conkyengha-ni? most-Gen student-PL-Nom which professor-Acc like-Q

'Which professor most students like?'

(Beck \& Kim, 1997)

b. Taypwupwun-uy haksayng-tul-i nwukwu-lul hoycang-ulo

most-Gen student-PL-Nom who-Acc president-as

chwuchenha-yss-ni?

recommend-Past-Q

'Who did most students recommend as president?'

(Kim, 2002)

In the two sentences of (17), the quantifier 'most' does not show intervention effects. As such, scope rigidity and intervention-hood is not always correlated.7) Erlewine \& Kotek's (2017) scope-based analysis does not properly elucidate the intervention phenomenon of Korean.

Furthermore, let us consider that referential NPs such as proper nouns or pronouns are not involved in intervention effects. ${ }^{8)}$ Although they do not take part

7) A reviewer asks me to consider an example that contains nwukwuna 'everyone'.

(i) Nwukwuna-ka oci anh-ass-ta. (ambiguous)

everyone-Nom come-CI Neg-Past-Decl.

'everyone didn't come'

a. $\sqrt{ }$ No one came.

b. $\sqrt{\text { Everyone did not come. }}$

The sentence (i) shows the two interpretations as presented in a. and b. The scope ambiguity makes us to predict that the quantifier 'everyone' will not yield an intervention effect; however, wh-questions including the quantifier turn out to have relatively low acceptability scores in this experimental study (see Figure 1 and Table 5) although they are judged to be felicitous by the reviewer.

(ii) ?? Nwukwuna-ka mwues-ul mekess-ni?

everyone-Nom what-Acc eat-Past-Q

'What did everyone eat?'

As with taypwupwun, the Korean quantifier nwukwuna cannot be analyzed from the perspective of E\&K (2017).

One more thing to note is that there can be a certain situation that enables the sentence to make sense as the reviewer judged. The situation will surely be the one the interlocutor already knows that there is a specific food everyone ate. Without this assumption, the sentence is hard to obtain acceptability. Different acceptability judgments that can be made in (ii) are related to how an interlocutor/addressee interprets a quantifier within a context, which is the main argument of this paper.

8) A reviewer points out that NPs such as Minswu-man yield intervention effects although it contains a proper name.

However, responsible for the intervention effect is 'only, not the NP Minswu.

(i) *Minswu-man $/ \sqrt{ }$ Minswu-ka mwues-ul mek-ess-ni?

Minswu-only/ Minswu-Nom what-Acc eat-Past-Q

'What did only Minswu eat?'

Minswu-man does not denote a referential individual even though Minswu itself is referential. See section 4.3 for more details. 
in scope relations, they are said to have widest scope as a part of the presupposition. Given the fact that referential items such as the man and Jenny are irrelevant to intervention effects, we can predict that a scopally specific item (i.e., scope-rigid quantifiers) is unlikely to induce intervention. In this regard, E\&K's (2017) claim that scope-rigidity causes intervention is unconvincing.

Partitive specificity also does not provide an effective account of the intervention phenomenon. Patitive NPs considered as specific NPs yield intervention effects as exemplified below.

(18) *John, Mary, Jenny cwungey nwukwunka-ka mwues-ul kacyewass-ni? John, Mary, Jenny among someone-Nom what-Acc brought-Q 'What did someone among John, Mary and Jenny bring?'

In (18), though the NP including a quantifier possesses a partitive specificity, intervention effects do not disappear. In other words, despite the fact that 'someone' is "specific" in terms of partitivity, it does not allow the successful interpretation of the wh-phrase. So far we have observed that scopal specificity and partitive specificity are not enough to address the issue of intervention. Instead, the concept of epistemic specificity can provide a unified account of intervention-related data. In (18), the partitive NP including the quantifier 'someone' is epistemically nonspecific and consequently the sentence is unacceptable.

Lastly, I point out that specificity should be evaluated in the perspective of the addressee in interrogative sentences (here, wh-questions) based on the non-trivial fact that interrogatives are addressee-oriented (Tenny, 2006). Even though the speaker has a specific referent in their mind, the addressee may not. In (18), it is hard for the addressee to recognize which person 'someone' refers to, i.e., whether 'someone' is John, Mary, or Jenny although the speaker has in mind an intended referent of 'someone'. Thus, I propose that the addressee's perceiving a quantificational subject as non-specific in a wh-question is a key factor in causing an intervention effect. To provide reliable evidence for the claim, this paper employs formal experimental methods. Prior to discussing experimental design and results, we will examine in the next section amelioration effects that are an important topic that should be addressed in exploring intervention phenomena. 


\subsection{Amelioration effects}

There are three phenomena in which intervention effects are overridden: Scrambling effects, Embedding effects, and D-linking effects. We need to compare when intervention arises and when it is cancelled since it can provide a clue of what determines intervention effects. First, when a wh-in situ phrase is placed above/before a potential intervener via scrambling, its interpretation is not interfered with (Scrambling effects).

(19) a. Mwues-ul nwukwuna-ka ilk-ess-ni? what-Acc everyone-Nom read-Past-Q 'What did everyone read?'

b. Mwuesul nwukwunka-ka ilk-ess-ni? what-Acc someone-Nom read-Past-Q 'What did someone read?'

The post-wh position of the intervener appears to guarantee an amelioration effect. Tomioka (2007) proposes a prosodic condition for the scrambling effect. When a wh-phrase is scrambled, the phrase boundary is shifted to the left with the scrambled $w h$ and the post $w h$-meterial gets prosodically reduced. Interveners (Anti-Topic Items) are placed in the prosodically reduced position (part of the tail portion of the sentence) and turns to old information, thereby canceling intervention effects. However, as Kim (2018) pointed out, her information structure-based analysis does not hold true for examples like (20).

\section{(20) Mwues-ul, YONA-man, Mina-hantey cwu-ess-no? what-Acc [YONA-ONLY] Mina-to give-Past-wh-Q?} 'What did only Yona give to Mina?'

(Kim, 2018)

This example inserts a pause after the wh-phrase and places emphasis on the following phrase, Yona-man 'only Yona'. Even though 'only Yona' is no longer in a phonologically reduced position, the sentence is acceptable.

Tomioka (2007) also focuses on another amelioration effect; embedded contexts show much weaker intervention effects (Embedding effects). Although a wh-element is in syntactically disadvantageous position to obtain its successful interpretation (i.e., below an intervener), the structure is considered to be felicitous. 
(21) Ne-nun [CP nwukwuna/nwukwunka-ka mwues-ul ilk-ess-ta-ko] you-Top. everyone/someone-Nom what-Acc read-past-dec.-comp sayngkakha-ni?

think-Q

'What do you think that everyone/someone read?'

(Tomioka, 2007)9)

As for this improvement effect, he explained that since an intervener is interpreted as an old information by embedding, intervention effects are obliterated. Yet, we will see in section 3.3.2 and 3.3.3 that the two quantifiers ('everyone' and 'someone') presented in (19) and (21) tend to have low acceptabilities in embedded as well as scrambled contexts. These 'weak' amelioration effects cannot be elucidated in terms of his information structural analysis.

The preceding section has shown that the essential property of interveners is epistemic non-specificity. The fact that the two quantifiers tend to be construed as non-specific in almost all structural environments ('scrambled' or 'embedded') is closely linked to the addressee-oriented property of a wh-question. It is less likely for the addressee to have a particular referent for 'everyone' and 'someone' and thus this can account for the tendency of having low acceptabilities. On the other hand, if a potential intervener becomes a recognized entity by an addressee in a certain context, intervention effects will not ensue. It is not conclusive which position an intervener occupies in a syntactic/information structure.

Lastly, let us discuss the D-linking effects of a wh-in situ. In the literature, D-linked wh-elements such as which-phrase tend to improve otherwise ungrammatical sentences. For instance, D-linked wh-phrases do not obey Superiority condition and weak island constraints and nonetheless yield grammatical sentences. Is the cancellation effect of a D-linked wh-phrase applicable to quantificational interveners? No prior studies have addressed this issue. Although Ha (2004) handles D-linking effects in the intervention context, he uses only examples including focusing elements without regard to quantificational interveners. He argues that D-linked/specific wh-phrases ${ }^{10)}$

9) Tomioka (2007) posits that Korean examples have the same acceptabilities as Japanese ones in his paper; however, I cannot agree with his grammaticality judgment in examples like (20). In fact, more than a few Korean studies have tended to translate Japanese examples to Korean ones following the Japanese acceptability judgments without a discreet investigation. This is one of the important reasons why this study starts with a formal experiment.

10) In the literature, specificity and D-linking are used interchangeably; however, they need to be separate. Being D-linked means that an element comes from a certain discourse set. Given this definition, the notion of specificity is more sophisticated to describe how the interlocutor perceives 
defy intervention effects even if they are c-commanded by a scope bearing element (i.e. a potential intervener) in a syntactic structure since they can get their scope via unselective binding11). Let us examine an example in which a quantifier is used instead of a focusing item in his examples.

(22) Nwukwunka-ka i salamtul cwungeyse nwukwu-lul cohaha-ni? someone-Nom these people among who-Acc like-Q 'Which one among these people does someone like?'

(adapted from Ha, 2004)

Following his logic, we have to say about (22) that the wh-phrase is successfully interpreted by means of its D-linking property regardless of the type of the quantifier. However, it is not the case. Section 3.3.4 will show that the D-linking property of a wh-in situ cannot be the only contributing factor to override the intervention effect and how a quantificational subject is construed (e.g., non-specific or specific) is more conclusive.

To conclude this section, most previous studies have failed to account for all aspects of the intervention phenomenon from the perspective of the interaction of intervention effects and amelioration effects. This study tests through formal acceptability judgment experiments whether the D-linking property of a wh-phrase ameliorates the illegitimacy of a sentence, whether a wh-phrase preceding a potential intervener via scrambling offsets the intervention effect, and whether when the wh-question involving an intervener is embedded in a matrix sentence, the acceptability improves. Based on the investigation of the presence/absence of those three amelioration effects and the degree of increasing acceptability, we will discuss what is accountable for intervention effects.

\section{Experiments}

\subsection{Objectives}

The purpose of the experiment is to answer these five questions below and to

an item (as we saw in section 2.2) than the notion of D-linking. Nevertheless, this paper use the term 'D-linking' when we describe the property of a 'wh-phrase' for the convenience of explanation.

11) According to Pesetsky (1987), D-linked wh-phrases are licensed via unselective binding unlike non-D-linked wh-phrases that are sensitive to movement-oriented constraints. 
ultimately figure out how each quantifier is connected/disconnected with its intervening property. First, when a quantificational subject is used in a wh-question, how (un)acceptable is the sentence? Are there significant distinctions among quantifiers? The experiment targets 5 quantifiers that are relatively controversial: nwukwuna 'everyone', nwukwunka 'someone', numeral quantifiers such as three, -isang 'more than', and -miman 'fewer than'.12)13)

$\begin{array}{ccccc}\text { Quantifier } 1 \cdots & \text { wh } & \cdots & \text { ? } \\ \text { vs. Quantifier } 2 & \cdots & \text { wh } & \cdots & \text { ? } \\ \text { vs. Quantifier } 3 & \cdots & \text { wh } & \cdots & \text { ? }\end{array}$

Second, how significantly does a certain context affect acceptability judgments? We compare sentences sharing the same quantifier in different contexts. A total of two situations for comparison are presented in the experiment. ${ }^{14)}$ To illustrate, Context $\mathrm{A}$ is that "at a potluck party, a friend who arrived later is asking another friend who arrived earlier." Context B is that "A survey about whom to respect was performed aimed at students in a class. Student A is asking student B who knows about the result in which who respects whom is listed." In each situation, whquestions including 5 quantifiers are tested. Does each of the quantifiers have the same degree of acceptability both in context A and B?

\begin{tabular}{|c|c|c|}
\hline \multicolumn{3}{|l|}{ Context A } \\
\hline Quantifier $1 \cdots$ & wh & \\
\hline Quantifier $2 \ldots$ & wh & \\
\hline
\end{tabular}

vs.

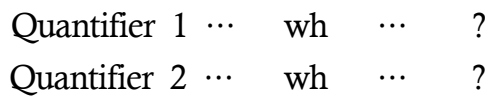

12) For the ease of explanation, nwukwuna is represented as 'everyone' although there is no one-to-one correspondence between the Korean quantifier nwukwuna and the English one everyone.

13) Prior to the main survey, a preliminary survey was conducted which contains taypwupwun 'most' and manhun 'many' in addition to the 5 quantifiers to make sure if the survey is understandable for participants and to decide which quantifiers we will use for experimental items. Based on the results, 'most' and 'many' were excluded in the main survey since they show higher acceptabilities (mean acceptability: 6.33 and 5.78 respectively) and they have been regarded as non-interveners without different opinions in previous literature.

14) It would help obtain more precise results on the effect of contexts if we use more various (more than two) situations in the experiment. However, as it will substantially increase the number of experimental items and consequently give the survey participants additional judgment tasks, an extra burden, we kept the number of situations to the minimum. 
Third, we examine if D-linked wh-phrases can emasculate quantificational interveners. Only if a D-linked wh-phrase is used, is the sentence acceptable irrespective of the property (specific/non-specific) of a quantificational subject?

(25)

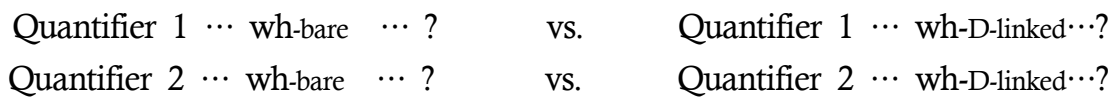

Fourth, scrambling of an intervenee (i.e., wh-in situ) to the position higher than an intervener (i.e., quantifier) tends to offset intervention effects. Is it true in Korean examples?

(26)

$\begin{array}{lll}\text { Quantifier } 1 \cdots \text { wh } \cdots \text { ? } & \text { vs. } & \text { Wh } \cdots \text { Quantifier } 1 \cdots \text { twh? (scrambled) } \\ \text { Quantifier } 2 \cdots \text { wh } \cdots \text { ? } & \text { vs. } & \text { Wh } \cdots \text { Quantifier } 2 \cdots \text { twh? (scrambled) }\end{array}$

Lastly, while the cancellation effects of scrambling have been maintained by a number of researchers, those of embedding have not been addressed in Korean literature. We investigate if various Korean quantifiers display amelioration effects in 'embedded contexts'. When a wh-question including an intervener is realized as an embedded clause in a matrix question, is the existing intervention effect ameliorated without exceptions?

(27)

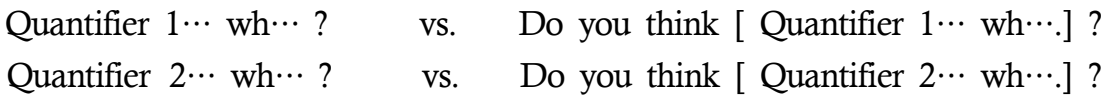

\subsection{Methods}

100 undergraduate or graduate students at Kyungpook National University and Pusan National University, native speakers of Korean, participated in this experiment. Participants were tested individually and asked to judge for the acceptability of the sentences on a 7-point Likert scale (1 corresponding to a totally unacceptable sentence and 7 to a perfectly acceptable sentence). In order to familiarize themselves with the Likert scale, participants were first shown 3 examples of sentences (one corresponding to a totally unacceptable sentence, one 
corresponding to a nearly acceptable sentence, one corresponding to a perfectly acceptable sentence) and their respective ratings, none of which is relevant to 'intervention', the topic of this study. After the exercise session, the main survey was begun. In addition to simply marking a score in the survey, when they gave scores lower than 3 to a sentence, they were asked to write the reason why they gave relatively low scores. ${ }^{15}$ ) This helped in identifying the specific reasons for their judgments. ${ }^{16)}$ The time to complete the experiment was approximately $40 \mathrm{~min}$. The results of 15 participants have been excluded leaving 85 in total; they didn't complete the survey or marked 'almost acceptable' ( 6 or 7 ) in all the sentences.

Experimental items were all wh-questions and were prepared using a $5 \times 4 \times 2$ design, crossing subject type (5 quantifiers), type of structure (Basic vs. D-linked wh vs. Scrambled vs. Embedded), and contexts (two situations). $20\left(5^{*} 4\right)$ items of lexically matched stimuli in each context were created and 30 filler items were added to the experimental items in order to introduce some variability. The filler items are yes/no questions including target quantifiers or non-quantifiers and wellformed wh-questions. ${ }^{17)}$ There were 50 items in each context, 100 items altogether.

Table 1. Experimental conditions

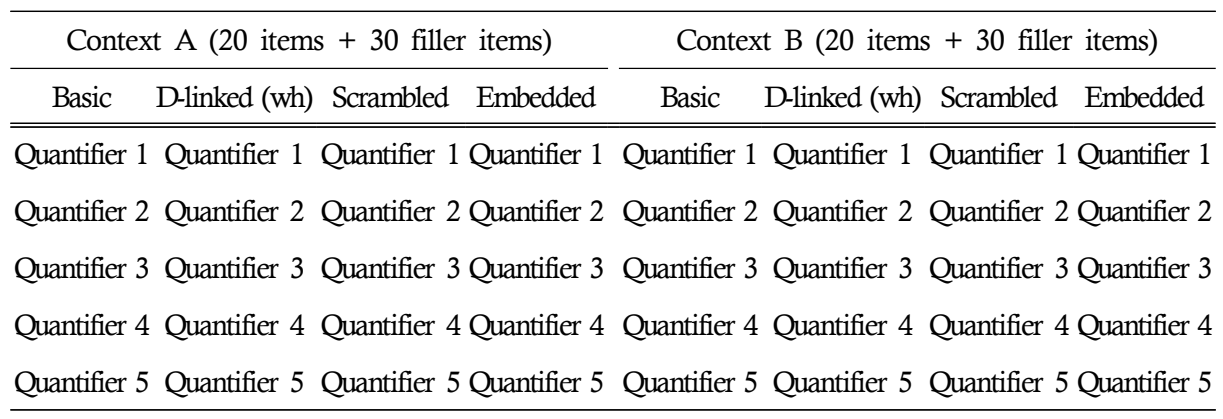

Note: Q (uantifier) 1: nwukwuna 'everyone', Q2: nwukwunka 'someone', Q3: numeral Q (uantifier), Q4: -isang 'more than N', Q5: -miman 'fewer than N'.

15) These subjective questions are limited to 'basic' types of sentences in the interest of time.

16) By adopting (partially) qualitative research, this study is able to discuss some cognitive effects behind simple figures in the results. Previous works have not attempted a hybrid experimental approach combining quantitative and qualitative research.

17) Examples of filler sentences are as follows. someone/Mina-Nom pizza-Acc brought?
'Did someone/Mina bring pizza?'
(i) Nwukwunka/Mina-ka phica-lul kacyewasse? (y/n question)
(ii) Mina-ka mwues-ul kacyewasse? (well-formed wh-question)
Mina-Nom what-Acc brought?
'What did Mina bring? 
Examples of the stimuli used in each context are presented below in Table 2 and 3. The participants are instructed to read a situation corresponding to context A first and evaluate the acceptabilities of 50 sentences within the context, and then given the next situation (context B) and do the same task.

Table 2. Example stimuli (Context A; At a potluck party, a friend who arrived later is asking another friend who arrived earlier.)

\begin{tabular}{|c|c|}
\hline Condition & Stimuli \\
\hline Basic & $\begin{array}{l}\text { Nwukwunka-ka mwues-ul kacyew-ass-e? } \\
\text { someone-Nom what-Acc bring-past-Q } \\
\text { 'What did someone bring?' }\end{array}$ \\
\hline D-linked (wh) & 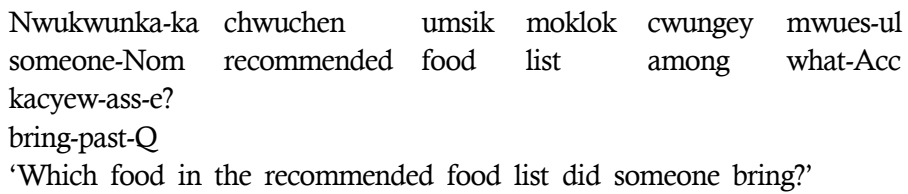 \\
\hline Scrambled & $\begin{array}{l}\text { Mwues-ul nwukwunka-ka kacyew-ass-e? } \\
\text { what-Acc someone-Nom bring-past-Q } \\
\text { 'What did someone bring?' }\end{array}$ \\
\hline Embedded & $\begin{array}{l}\text { Ne-nun [nwukwunka-ka mwues-ul kacyew-ass-ta-ko] sayngkakha-ni? } \\
\text { you-Top someone-Nom what-Acc bring-past-dec.-comp think-Q } \\
\text { 'What do you think that someone brought?' }\end{array}$ \\
\hline
\end{tabular}

Table 3. Example stimuli (Context B; A survey about whom to respect was performed aimed at students in a class. Student A is asking student B who knows about the result in which who respects whom is listed.)

\begin{tabular}{|c|c|}
\hline Condition & Stimuli \\
\hline Basic & $\begin{array}{l}\text { Sey myeng isang-i nwukwu-lul conkyengha-ni? } \\
\text { three CL more-Nom who-Acc respect-Q } \\
\text { 'Who do more than three (people) respect?' }\end{array}$ \\
\hline D-linked (wh) & 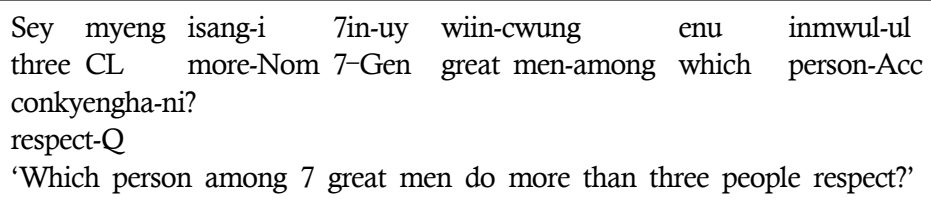 \\
\hline Scrambled & $\begin{array}{l}\text { Nwukwu-lul sey myeng isang-i conkyengha-ni? } \\
\text { who-Acc three CL more-Nom respect-Q } \\
\text { 'Who do more than three (people) respect?' }\end{array}$ \\
\hline Embedded & $\begin{array}{l}\text { Ne-nun [Sey myeng isang-i } \quad \text { nwukwu-lul } \\
\text { you-Top three CL more-Nom who-Acc } \\
\text { sayngkakha-ni? } \\
\text { think-Q } \\
\text { 'What do you think that more than three respect?' }\end{array}$ \\
\hline
\end{tabular}


The difference between context $\mathrm{A}$ and context $\mathrm{B}$ lies in how much concrete knowledge/information the addressee holds about the subject/contents being asked by a wh-question. To illustrate, in context $\mathrm{A}$, it is not certain that the addressee knows detailed information about who brought what food at the party even though he/she arrives earlier than the speaker. In contrast, context B assumes that the addressee has specific information about who respects whom in the survey. The purpose of setting the dissimilar contexts is to investigate if the difference of context and the knowledge of an addressee influences the acceptability judgment of a sentence.

Meanwhile, D-linked wh-questions contain more concrete contents related to a wh-word compared to basic correspondents. In other words, they provide a pre-established discourse set for the interpretation of a wh-word. For instance, in the D-linked version of Table 2, the set from which a food is picked for the answer is restricted to the set of the recommended food list. Likewise, in Table 3, the D-linked wh-question shows that the set for a wh-phrase is regulated by the set of 7 great men. Note that the D-linkedness of a wh-word should be considered separately from the specificity of a quantificational item; thus we are differentiating the original wh-questions from the D-linked ones to examine how significantly the D-linked property of a wh-in situ affects the acceptability of a sentence.

\subsection{Results and discussion}

\subsubsection{Quantifers, contexts, and intervention effects}

We used a two-way repeated measure ANOVA (analyses of variance) to observe the influence of quantifiers and contexts as well as the interaction of these two factors. The results revealed significant effects of each of these factors and significant interaction effects as indicated below.

Table 4. Two-way repeated measure ANOVA

\begin{tabular}{ccc}
\hline Source & $\mathrm{F}$ & $\mathrm{p}$ \\
\hline \hline Quantifiers & 110.224 & $<.001$ \\
Contexts & 114.247 & $<.001$ \\
Quantifiers * contexts & 15.158 & $<.001$ \\
\hline
\end{tabular}


Figure 1 shows the relative acceptability of 5 quantifiers and the effect of the context. We can see that there is a significant difference in acceptability among quantifiers and 'everyone' and 'someone' display relatively low scores.

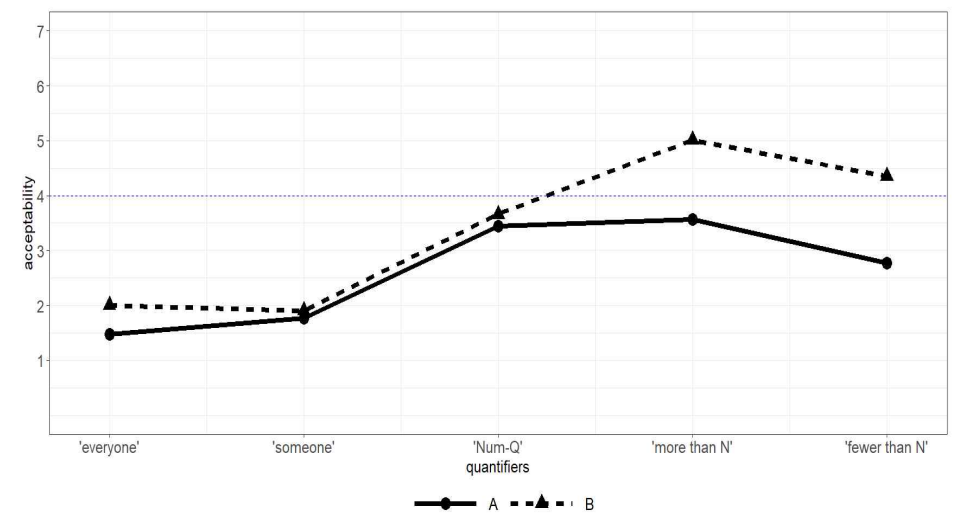

Figure 1. Quantifiers and intervention effects in context A and B.

The dotted line represents context A and the solid line represents context B. It is observed that the mean acceptability of context B is higher than that of context A (The dotted line is above the solid line). Also, we can see the dots are almost overlapping in 'someone' and numeral quantifiers; the two do not exhibit significant differences in acceptability between the two types of contexts. In quantifiers other than the two, the interaction between a quantifier and a context reached statistical significance. The exact figures are presented below.

Table 5. Mean acceptability

\begin{tabular}{lcccc}
\hline \multicolumn{1}{c}{ Quantifiers } & Context A & Context B & $\mathrm{t}$ & $\mathrm{p}$ \\
\hline \hline a. nwukwuna 'everyone' & $1.47 \pm 0.83$ & $2.00 \pm 1.44$ & -3.848 & $<.001$ \\
b. nwukwunka 'someone' & $1.76 \pm 1.02$ & $1.91 \pm 1.26$ & -1.255 & .213 \\
c. numeral Q (uantifier) & $3.45 \pm 1.76$ & $3.66 \pm 1.69$ & -1.318 & .191 \\
d. -isang 'more than N' & $3.56 \pm 1.91$ & $5.01 \pm 1.68$ & -6.564 & $<.001$ \\
e. -miman 'fewer than N' & $2.78 \pm 1.60$ & $4.35 \pm 1.84$ & -8.036 & $<.001$ \\
\hline
\end{tabular}

Given the higher mean acceptabilities of context B, we can say that contexts play a nontrivial role in determining the (un)acceptability of quantifiers despite the fact 
that 'someone' and Num-Qs do not have "significantly" high 'context effects'. It suggests that a quantifier may possess an intervening property or not depending on the given context. This result can explain why there have been dissimilar judgments on the same sentence when the context is not given.

Let us discuss the quantificational items that exhibit (relatively) low scores: 'someone' and 'everyone'. Of the two, 'someone' did not show significant differences between either context. About $93 \%$ of the participants gave scores lower than 3 to 'someone', of which about $52 \%$ gave the reason for that as the following: ${ }^{18)}$

(28) "Nwukwunka is not specific. I don't know who that person is."

As for numeral quantifiers such as ney myeng 'four people', about $60 \%$ of the participants gave scores under 3 , of which $74.5 \%$ answered about the reason like this:

(29) "It's difficult to know which group of people that number indicates."

In addition, five of the nine participants who gave a score of 4 described the reason for that: "I gave 4 points because the sentence can be interpreted in two ways; if there are four specific people and we are talking about them, the sentence is acceptable but if there isn't a certain group of people we can make a reference to, the sentence is unacceptable." These comments taken as a whole suggest that an intervening factor is linked to 'non-specific' property.

In the cases of -isang and miman, we saw the same reasons for why the participants marked lower acceptabilities (under 3 points); for instance, they said that quantificational expressions such as ney myeng isang 'more than 4 people' and yeses myeng miman 'fewer than 6 people' do not refer to a specific group. Also, let us note that these quantifiers have "significant" variation in judgments depending on the context (as seen in Figure 1 and Table 5). In other words, the gap between the two contexts is relatively wider when compared with other quantifiers. Why were they given higher grades in context B than context A? Context B presupposes that the addressee knows specific information about 'who respects whom' (the

18) Unlike 'someone', most of the participants that gave lower scores to 'everyone' responded for the reason like this: the expression nwrikwnna itself sounds awkward in wh-questions. A small number of the respondents mentioned the non-specificity of 'everyone' as a reason. 
subject about which the wh-questions are asking). It seems that the presupposition enables questions about 'more than' or 'fewer than' numerals to become readily understandable; those quantifiers are more likely to be interpreted as a specific group of people in context B.

Given the findings reported above, we can say two things. First, if an interlocutor recognizes a quantifier as 'non-specific', the wh-question cannot be interpreted, whereas if they perceive the quantifier as a specific individual/group, the interpretation of the wh-in situ is not hindered. Second, contexts contribute to determining if a quantifier serves as an offending element. Accordingly, judging sentences (especially, those with inconsistency over acceptability) without proper regard to the context and discourse should be eschewed. Previous studies have ignored or underestimated how the context can affect the intervention phenomenon but it needs to be taken into account. Even though this article emphasizes the effect of context, it does not mean that contexts do everything for the cancellation of intervention effects. Considering that 'everyone' and 'someone' exhibit lower acceptabilities in either context, they tend to be interpreted as 'non-specific' not strongly affected by context. To illustrate, it is rare to use nwukwunka 'someone' to refer to a "specific" person in a wh-questions. ${ }^{19)}$ It is much more natural to use a proper noun and pronoun when conversation participants talk about the same person. The tendency of non-specific/specific reading of a quantifier is also a consideration.

\subsubsection{Scrambling effects}

This section shows and discusses the results of how much the sentences improve via scrambling of wh-in situ phrases. The 3-way repeated measure ANOVA indicated that each factor (e.g., quantifiers, contexts, and scrambling) has significant effects and there is significant interaction among the three factors.

19) In interrogatives, the epistemic state of the addressee is crucial in evaluating the truth of a proposition (Tenny, 2006). When 'someone' is used in a wh-question, the addressee is less likely to interpret it as a particular person even if the speaker has his/her intended referent in mind. To refer to a certain individual, 'someone' is an unfavored option to conversation participants, especially the addressee, since there are better options such as proper nouns and pronouns. We will see more details in section 4.1 and 4.2 . 
Table 6. 3-way repeated measure ANOVA (scrambling)

\begin{tabular}{ccc}
\hline Source & $\mathrm{F}$ & $\mathrm{p}$ \\
\hline \hline Basic & 36.071 & .000 \\
Quantifiers & 102.093 & .000 \\
Contexts & 217.076 & .000 \\
Scrambled * quantifiers & 14.317 & .000 \\
Scrambled * contexts & 8.432 & .005 \\
Quantifiers * contexts & 10.980 & .000 \\
Scrambled * quantifiers * contexts & 7.541 & .000 \\
\hline
\end{tabular}

The Figure 2 presented below displays the contrast of basic sentences and scrambled ones in each context.
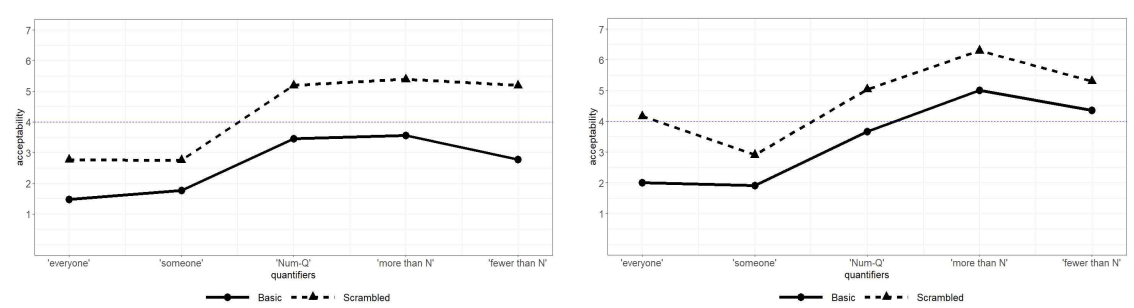

Figure 2. Basic vs. Scrambled (Left: context A, Right: context B).

In both context $\mathrm{A}$ and context $\mathrm{B}$, all the items that undergo scrambling show significantly higher acceptabilities.

The results of a paired sample t-test are as follows; we can see the change of the mean estimate between the basic sentences and the scrambled ones with the exact figures.

Table 7. Scrambling effects

\begin{tabular}{lccccccccc}
\hline & \multicolumn{4}{c}{ Context A } & & \multicolumn{4}{c}{ Context B } \\
\cline { 2 - 4 } & Basic & Scrambled & $\mathrm{t}$ & $\mathrm{p}$ & & Basic & Scrambled & $\mathrm{t}$ & $\mathrm{p}$ \\
\hline \hline a. 'everyone' & $1.47 \pm 0.83$ & $2.76 \pm 1.94$ & -6.470 & $<.001$ & & $2.00 \pm 1.44$ & $4.16 \pm 2.28$ & -8.824 & $<.001$ \\
b. 'someone' & $1.76 \pm 1.02$ & $2.75 \pm 1.85$ & -5.169 & $<.001$ & & $1.91 \pm 1.26$ & $2.91 \pm 1.86$ & -4.830 & $<.001$ \\
c. numeral-Q & $3.45 \pm 1.76$ & $5.19 \pm 1.70$ & -7.906 & $<.001$ & & $3.66 \pm 1.69$ & $5.04 \pm 1.91$ & -5.533 & $<.001$ \\
d. 'more than N & $3.56 \pm 1.91$ & $5.39 \pm 1.94$ & -7.551 & $<.001$ & & $5.01 \pm 1.68$ & $6.29 \pm 1.32$ & -7.386 & $<.001$ \\
e. 'fewer than N & $2.78 \pm 1.60$ & $5.19 \pm 1.98$ & -11.242 & $<.001$ & & $4.35 \pm 1.84$ & $5.31 \pm 1.80$ & -4.475 & $<.001$ \\
\hline
\end{tabular}


It is obvious that scrambling effects are statistically significant across quantifiers. Nonetheless, we need to consider that the "significant" change of acceptability by scrambling does not always guarantee perfect grammaticality. In the case of 'someone', its mean estimate is still (relatively) low (2.75 and 2.91) in the scrambled version. The following sentences are the items used in the context $\mathrm{A}$ and $\mathrm{B}$ respectively in the experiment; they were judged as rather infelicitous even though the wh-words are not within the scope of the interveners.

(30) a. ?? Mwues-ul nwukwunka-ka kacyew-ass-e?

(mean estimate: 2.75 )

what-Acc someone-Nom bring-past-Q

'What did someone bring?'

b. ?? Nwukwu-lul nwukwunka-ka conkyengha-ni? (mean estimate: 2.91) who-Acc someone-Nom respect-Q

'Who does someone respect?'

This challenges syntactic accounts on intervention effects; from the syntactic perspective, the higher position of a wh-phrase is directly connected to a wider scope reading in which means the intervener does not act on the wh-phrase at all. If it is on the right track, all quantifiers will have to show the same acceptability (i.e. 'completely acceptable') after scrambling a wh-in situ to the front. However, the prediction seems contradictory to the results of Figure 2 and Table 7 . We do not undervalue the significant effects of scrambling but attempt to point out some limitations of the pure syntactic approach to the intervention phenomenon. What is more important in circumventing intervention effects is whether a quantificational subject can have a specific interpretation.

\subsubsection{Embedding effects}

The experimental results show that embedding effects do not always occur. First, the result of the 3-way repeated measure ANOVA showed that each factor has significant effects and the interaction among the three factors (quantifiers, contexts, and embedding) is significant. 
Table 8. 3-way repeated measure ANOVA (Embedding)

\begin{tabular}{ccc}
\hline Source & F & $\mathrm{p}$ \\
\hline \hline Basic & 14.204 & .000 \\
Quantifiers & 75.333 & .000 \\
Contexts & 145.419 & .000 \\
Embedding * quantifiers & 10.205 & .000 \\
Embedding * contexts & 35.996 & .000 \\
Quantifiers * contexts & 7.670 & .000 \\
Embedding * quantifiers * contexts & 7.878 & .000 \\
\hline
\end{tabular}

In the Figure below, we can observe the relations of a quantifier and an 'embedded' circumstance are somewhat different in each context.
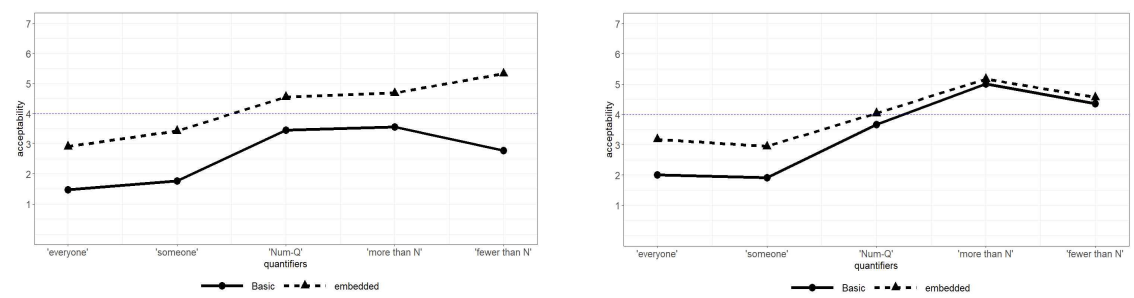

Figure 3. Basic vs. Embedded (Left: context A, Right: context B).

In context $\mathrm{A}$, all types of quantifiers show significantly higher acceptabilities in the 'embedded' conditions. On the other hand, in context B, only 'everyone' and 'someone' show significantly higher acceptabilities in the 'embedded' conditions compared to the 'basic' ones; by contrast, there is no significant difference between basic types and embedded types in the other three quantifiers (see (c), (d), and (e) in Table 9 for the exact figures).

Table 9. Embedding effects

\begin{tabular}{|c|c|c|c|c|c|c|c|c|}
\hline & \multicolumn{4}{|c|}{ Context A } & \multicolumn{4}{|c|}{ Context B } \\
\hline & Basic & Embedded & $\mathrm{t}$ & $\mathrm{p}$ & Basic & Embedded & $\mathrm{t}$ & $\mathrm{p}$ \\
\hline a. 'everyone' & $1.47 \pm 0.83$ & $2.91 \pm 1.95$ & -7.185 & $<.001$ & $2.00 \pm 1.44$ & $3.18 \pm 2.02$ & -4.872 & $<.001$ \\
\hline b. 'someone' & $1.76 \pm 1.02$ & $3.42 \pm 1.97$ & -7.567 & $<.001$ & $1.91 \pm 1.26$ & $2.94 \pm 1.77$ & -5.886 & $<.001$ \\
\hline c. numeral-Q & $3.45 \pm 1.76$ & $4.55 \pm 1.82$ & -6.134 & $<.001$ & $3.66 \pm 1.69$ & $4.04 \pm 1.68$ & -2.145 & $<.001$ \\
\hline d. 'more than $\mathrm{N}$ ' & $3.56 \pm 1.91$ & $4.68 \pm 2.03$ & -4.637 & $<.001$ & $5.01 \pm 1.68$ & $5.16 \pm 1.62$ & -.858 & $<.001$ \\
\hline e. 'fewer than $\mathrm{N}$ ' & $2.78 \pm 1.60$ & $5.33 \pm 1.76$ & -12.040 & $<.001$ & $4.35 \pm 1.84$ & $4.56 \pm 1.80$ & -1.140 & $<.001$ \\
\hline
\end{tabular}


As in scrambling effects, we need to consider whether the degree of the effect is strong enough for the sentences to be judged as 'totally acceptable' by previous researchers. The consequences of embedding are not always satisfactory. Compared to other quantifiers, the two quantifiers 'everyone' and 'someone' display significantly low mean acceptabilities in both the basic and embedded contexts, according to the results of LSD (Least Significant Difference) test. The examples used in the experiment are demonstrated below.

(31) a. ??Ne-nun [ nwukwuna-ka mwues-ul kacyew-ass-ta-ko ] sayngkakha-ni? you-Top. everyone-Nom what-Acc bring-past-dec.-comp think-Q 'What do you think that everyone brought?'

b. ??Ne-nun [ nwukwunka-ka mwues-ul kacyew-ass-ta-ko ] sayngkakha-ni? you-Top. someone-Nom what-Acc bring-past-dec.-comp think-Q 'What do you think that someone brought?'

It seems that the low-acceptabilities of (31) are attributable to the fact that 'every' and 'some' tend to be associated with 'non-specific' interpretation in wh-questions. As shown in section 3.3.1, most of the participants mentioned the property of being non-specific for the sentences they judged as unacceptable. Let us think about a sentence such as 'who do you think I saw yesterday?'. The sentence presupposes that there is $\mathrm{x}$, I saw $\mathrm{x}$ yesterday and asks for your thoughts about who the speaker saw. If 'someone' is used instead of ' $\mathrm{I}$ ' and the addressee cannot interpret it as a particular individual, the question is not legitimate. On the other hand, we can also account for cases in which embedding yields satisfactory results. If a quantifier is recognized to have a specific referent, it can be successfully interpreted like the sentence in which ' $\mathrm{I}$ ' is used.

\subsubsection{D-linking effects of wh-in situ phrases}

Lastly, let us consider results regarding how much the use of a D-linked wh-phrase is conducive to the obviation of intervention effects. The ANOVA revealed significant effects of each of these factors and significant interaction effects as indicated below. 
Table 10. 3-way repeated measure ANOVA (D-linked wh-in situ)

\begin{tabular}{ccc}
\hline Source & $\mathrm{F}$ & $\mathrm{p}$ \\
\hline \hline Basic & 101.261 & $<.001$ \\
Quantifiers & 68.268 & $<.001$ \\
Contexts & 144.283 & $<.001$ \\
D-linked wh* quantifiers & 14.640 & $<.001$ \\
D-linked wh* contexts & 8.705 & .004 \\
Quantifiers * contexts & 5.074 & $<.001$ \\
D-linked wh* quantifiers * contexts & 5.736 & $<.001$ \\
\hline
\end{tabular}

Figure 4 illustrates how strong or weak D-linking effects are in each context. In context A, all the quantifiers except for 'more than-' show significantly higher acceptabilities with D-linked wh-phrases. In context B, the D-linked conditions show significantly higher acceptabilities in all the quantifiers.
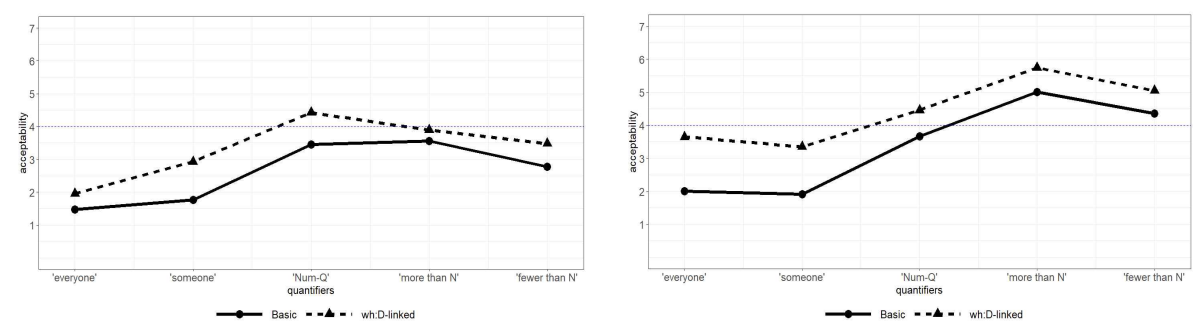

Figure 4. Basic vs. Wh:D-linked (Left: context A, Right: context B).

In either context, the mean acceptability is higher in D-linked sentences; notwithstanding we cannot conclude that the D-linking property of a wh-element obliterates intervention effects with respect to every quantifier. The results are not free from the question we raised in scrambling and embedding effects. How strong a D-linking effect is more important than the presence of the effect per se. As for 'eveyone' and 'someone', their acceptabilities are not close to the perfect score even in the D-linked version. There is a stronger contributing factor other than a D-linking effect in the cancellation of an intervention. Let us examine the part highlighted in bold in the following Table 11 . 
Table 11. D-linking effects

\begin{tabular}{|c|c|c|c|c|c|c|c|c|}
\hline & \multicolumn{4}{|c|}{ Context A } & \multicolumn{4}{|c|}{ Context B } \\
\hline & Basic & D-linked & $\mathrm{t}$ & $\mathrm{p}$ & Basic & D-linked & $\mathrm{t}$ & $\mathrm{p}$ \\
\hline a. 'everyone' & $1.47 \pm 0.83$ & $1.95 \pm 1.38$ & -3.642 & $<.001$ & $2.00 \pm 1.44$ & $3.65 \pm 2.00$ & -7.488 & $<.001$ \\
\hline b. 'someone' & $1.76 \pm 1.02$ & $2.93 \pm 1.94$ & -5.802 & $<.001$ & $1.91 \pm 1.26$ & $3.35 \pm 2.03$ & -7.217 & $<.001$ \\
\hline c. numeral-Q & $3.45 \pm 1.76$ & $4.42 \pm 1.89$ & -4.846 & $<.001$ & $3.66 \pm 1.69$ & $4.46 \pm 1.80$ & -4.132 & $<.001$ \\
\hline d. 'more than N' & $3.56 \pm 1.91$ & $3.89 \pm 1.82$ & -1.840 & .069 & $5.01 \pm 1.68$ & $5.74 \pm 1.57$ & -3.329 & .001 \\
\hline e. 'fewer than N' & $2.78 \pm 1.60$ & $3.48 \pm 1.80$ & -4.286 & $<.001$ & $4.35 \pm 1.84$ & $5.05 \pm 1.86$ & -3.001 & .004 \\
\hline
\end{tabular}

In context $\mathrm{A}$, when (d) and (e) meets a D-linked wh-phrase in a sentence, their mean acceptablities are 3.89 and 3.48 respectively. Meanwhile, in context $\mathrm{B}$, even when a D-linked wh-phrase is not used (Basic condition), their mean acceptabilities (i.e., 5.01 and 4.35) are higher than the D-linked types of context A. It implies that a context can make more contributions to generating the improvement of acceptability than D-linking property of a wh-element does. If a potential intervener can be recognized as a 'specific' individual in a certain context ('epistemic specificity'), even though a wh-phrase is not D-linked, the sentence is significantly acceptable. How the quantifier is perceived may be more decisive than whether the wh-phrase is D-linked or not. Let us remind ourselves (section 3.3.1) that most respondents mentioned that the unacceptability of a wh-question is on account of the non-specific characteristic of a quantificational subject.

${ }^{*}$ Quantifier $\quad \cdots$
epistemically
non-specific

When a quantifier is 'epistemically non-specific', it precludes a wh-question from being interpreted in spite of the D-linking of a wh-in situ. Being epistemically nonspecific means not perceiving an item as a particular individual in a given context.

\subsubsection{Summary and general discussion}

Let us summarize what we have examined so far. First, there are significant distinctions among quantifiers in intervention circumstances (basic type: < quantifier 
.. wh > order). Among them, 'everyone' and 'someone' show relatively low scores. Second, all the three amelioration effects (Scrambling, Embedding and D-linking effects) are observed overall; although some of the quantifiers do not exhibit statistically significant effects, the mean acceptabilities of the non-basic type of sentences (scrambled, embedded, D-linked) tend to be "higher" than those of the basic ones within a context. Nonetheless, this paper points out that the improved acceptability does not imply that the sentence is totally acceptable. In the literature, those three cancellation effects have been described as strong enough to apply to all elements; however, we observed in the experimental result that some cases (i.e., 'some' and 'every') show the tendency of having lower acceptability even though they have some improvement effects. Third, contexts play a critical role in the (un)acceptability of quantifiers, which suggests that an identical quantifier may be an intervener or not in accordance with how the addressee perceives a quantificational element. Relevant to this issue, there is a new finding of D-linking effects. Unlike the previous research $(\mathrm{Ha}, 2004)$, there are cases in which a D-linked wh-phrase does not emasculate an intervening element. ${ }^{20)}$ The epistemic specificity of a quantifier is more crucial than the D-linking property of a wh-phrase. Lastly, I claim that there is not a fixed/absolute set of intervening quantifiers. The binary classification (interveners vs. non-interveners) cannot account for the gradience in acceptability of a quantifier. Quantifiers are basically potential interveners in a wh-question considering that they are 'non-referential' items. To illustrate, the default status of a quantifier is [-specific] but if it is perceived as 'specific' in a certain context ('epistemically specific'), its status turns into [+specific] and does not incur intervention effects.

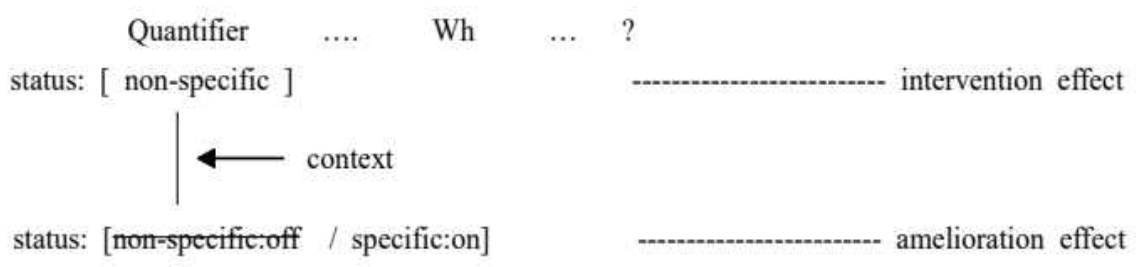

The point is that the property of being epistemically non-specific, not a certain

20) The result is quite surprising since it has been observed that D-linked wh-phrases yield grammatical sentences even when they violate syntactic constraints such as superiority and overt intervention effects. 
quantifier, leads to intervention effects. Without a context that enables the quantifier to be interpreted as a particular individual, all quantifiers are more or less unacceptable. From this perspective, we can understand why there are distinctive sets of intervening quantifiers among languages. In all languages, quantifiers are (potential) interveners in wh-questions but the only crosslinguistic difference rests on whether it is possible for them to change into non-interveners. In the next section, we will show why epistemic specificity in wh-questions (interrogatives) should be evaluated from the perspective of the addressee by introducing Tenny's (2006) speech act structure.

\section{Further Discussion}

\subsection{Addressee orientation}

To understand why the point-of-view of the addressee is critical in interrogative sentences, let us examine Tenny's (2006) Speech Act structure that contains the Sentience phrase. In the Speech Act projection, the agent of the speech act is the Speaker. Its theme is the information conveyed ('utterance content') and the goal is the Addressee.

The Speech Act Projection:

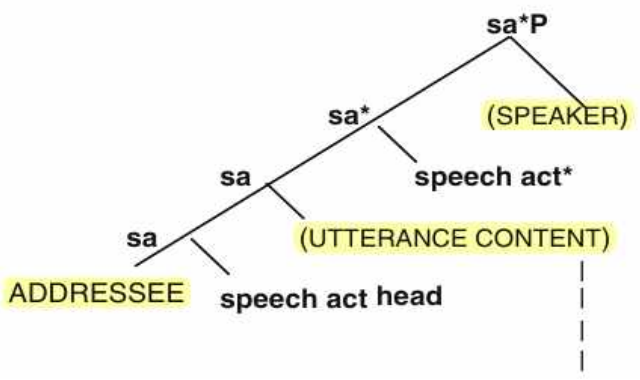

The Sentience/Evidentiality Phrase below the Speech act phrase has three arguments: the seat of knowledge, the proposition, and the context. 


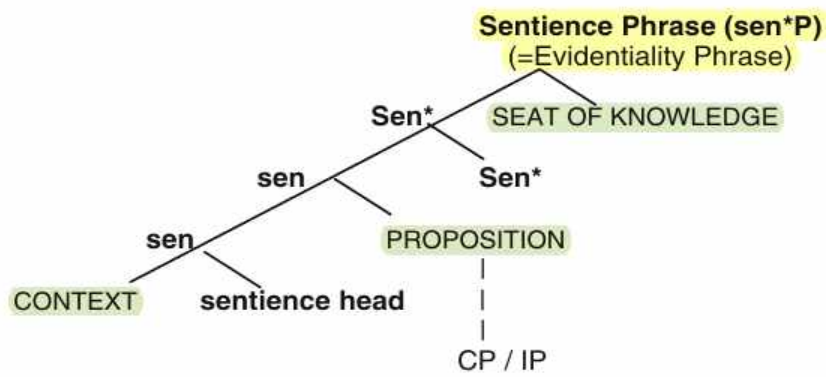

The Sentience/Evidentiality evaluates the truth of the proposition based on some knowledge or context known to the mind. The truth evaluation is Speaker-oriented in declarative sentences, whereas it is Addressee-oriented in interrogative ones.

(36) Interrogatives

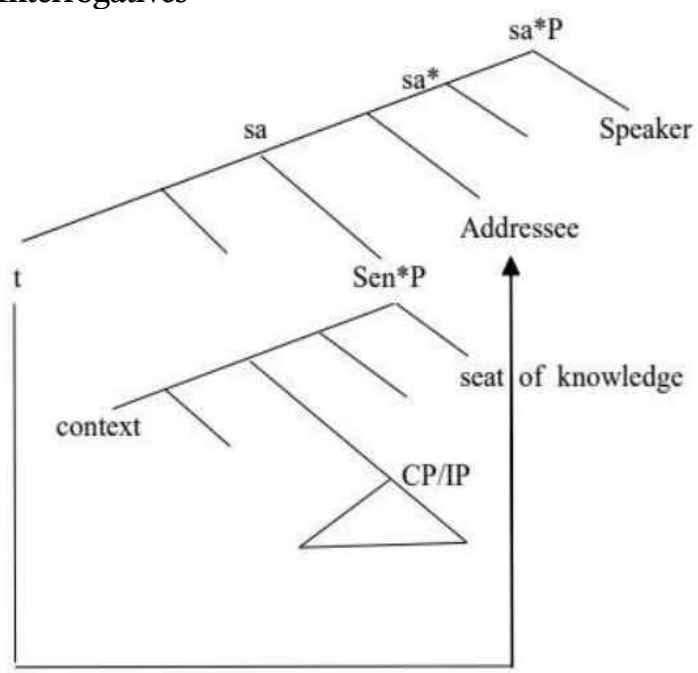

In the interrogative structure, the Addressee phrase moves above the Sentience phrase (but below the Speaker) and becomes the closest c-commander of the sentient/evidential argument. The Addressee holds the evidence for the truth of the proposition in their mind. Accordingly, whether a potential intervener serves as an offending element in a wh-question depends on how the addressee evaluates the proposition. The next structure is a refined version of (33). 


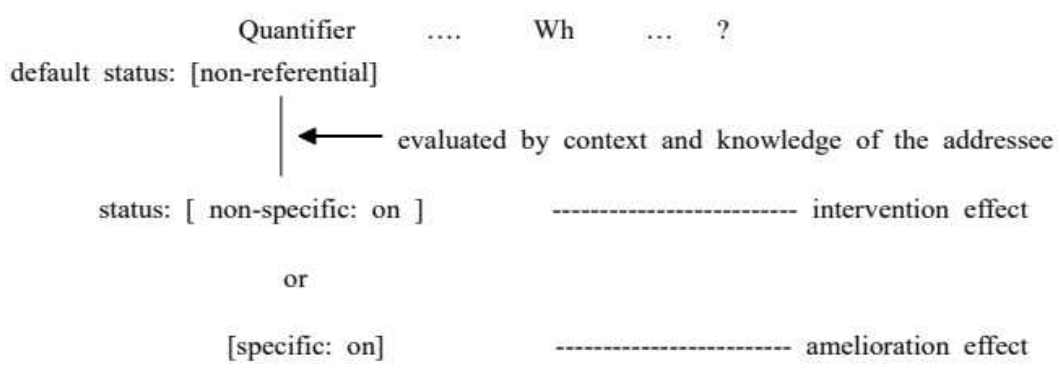

Quantifiers are in general non-referential. When it is used in a wh-question, it is assessed whether it refers to a particular individual or not by the context and knowledge of the addressee. Note that even if the speaker has a specific referent in their mind, the addressee can or cannot have the referent in their knowledge. If there is no grounds for a specific reading in the hearer's mind, the non-specific property of the quantifier interferes with the interpretation of the wh-phrase. On the other hand, if the addressee can devine which individual is being referred to in speaker's mind with their knowledge, the sentence will survive.

Let us reexamine a syntactic circumstance in which amelioration effects appear. One of the obvious ways to circumvent intervention effects is to put an intervenee in a position where there is no intervening element.

(38) scrambled: < wh... quantifier ...twh >

Previous studies have argued that the successful interpretation of a wh-phrase is assured in the environment like (38). However, some quantifiers (i.e., 'every' and 'some') showed not that high mean estimates even after scrambling (section 3.3.2). Previous literature cannot elucidate on these "weak" scrambling effects i.e., the gradient acceptability in scrambling contexts. Though a wh-word occupies a syntactically advantageous position (higher than an intervener) for the interpretation, it does not always yield complete acceptability. The availability of specific interpretation of a potential intervener (i.e., a quantifier) in discourse is more important than the syntactic position of an intervenee (i.e., a wh-in situ) in the overt syntax. Beyond the domain of the pure syntax, the intervention phenomenon should be understood at interfaces involved in semantics and pragmatics (Moon et al., 2009). 
4.2. No absolute (non-)specificity of quantifiers

This article has experimented 5 Korean quantifiers that are more or less contentious about their acceptability judgments: nwukwuna 'everyone', nwukwunka 'someone', numeral quantifiers, -isang 'more than N', and -miman 'fewer than N'. We have observed that nwukwuna 'everyone' and nwukwunka 'someone' tend to be construed as non-specific in all types of sentences (Basic, Scrambled, Embedded, and D-linked wh). A tendency is a tendency; this section will show the (non-)specific property of a quantifier is not fixed across languages.

Let us consider properties of English quantifiers in terms of specificity. In English, every does not pattern with some; the former is allowed in existential sentences but the latter is not.

(39) a. *There is every cow in the backyard.

(cf. *There is Elsie/her in the backyard)

b. There are some cows in the backyard.

According to Enç (1991), since "the specifics presuppose existence" and "presupposition of existence is incompatible with the assertion of existence", NPs defined as specific cannot occur in existential sentences. On the other hand, non-specific NPs are permissible in the relevant structures. In (39), the two quantifiers exhibit contrastive behaviors; the determiner every forms specific NPs and the determiner some non-specific ones.

Considering that the universally quantifying NP is specific in (39a), the tendency of the nonspecific readings of the Korean quantifier nwukwuna seems peculiar. However, in English, we can observe examples in which every-NPs are more likely to have a non-specific understanding.

(40) a. John, who has a Ph.D. in astrophysics, cheated on the exam.

b. A student in the syntax class, who has a $\mathrm{Ph}$. D. in astrophysics, cheated on the exam.

c. *Every student in the syntax class, who has a Ph.D. in astrophysics, cheated on the exam.

(Fordor \& Sag, 1982)

Non-restrictive relatives occur freely with definite expressions as in (40a) and in 
this light, the indefinite can naturally be understood referentially in (40b). However, the every-NP is not allowed in (40c); that is, every student cannot be construed as specific. The English quantifier every has shown in (39a) and (40c) that it has or does not have the same pattern with definites; that is, it is either specific or nonspecific.

Likewise, the Korean quantifier nwukwuna permits two kinds of readings, one of which will be selected depending on the context. We saw in the experiment that it favors a non-specific reading in wh-questions. On the other hand, if nwukwuna is used to refer to a certain group of people in a declaritive sentence, it can yield a specific reading.

(41) Nwukwuna-ka ameylikhano-lul cwumwunha-yss-ta. everyone-Nom Americano-Acc order-past-Dec.

'Everyone ordered Americano.'

In (41), nwukwuna does not refer to 'every man' on earth. The speaker talks about the contextually relevant people (e.g., every friend in this place) who are already in the domain of discourse. Enç (1991) states that "universal quantifiers in natural languages quantify over contextually given sets" and in this respect "all universal quantifying NPs are specific". In addition to Enç's definition for 'specificity' (i.e., the existence of a discourse set), the concept of 'specificity' should involve the existence of a specific referent in the speaker's mind. More precisely, (41) can be described like this: 'everyone' is 'specific' in that the speaker has a specific referent for a group referred to as 'everyone' from the contextually given set.21) Even though there cannot be a complete correspondence between the English quantifier everyone and the Korean quantifier nwukwuna, it is manifest that they share the basic property within the Universal Grammar. The two-fold interpretation of 'every' is available across languages and thus defining a quantifier as an absolute group (i.e., strong/weak quantifiers) may not be the best option.

Let us return to 'some'. The NP with the existential quantifier some is taken to be non-specific in (38b) but the deteminer does not always form non-specific NPs. As in the following example, when the determiner some forms a partitive NP, it is allowed in there-constructions yielding a specific reading.

(42) *There is some of the cows in the backyard.

(Enç, 1991)

21) Note that a referent does not need to be a single individual. A single group can be a referent. 
Also, we have often observed in the literature that 'some' per se can be interpreted as 'specific' although it is not used as a complex determiner some of the.

(43) a. Someone loves you.

b. Nwukwunka-ka ne-lul salanghan-ta. someone-Nom you-Acc love-Dec.

'Someone loves you'

If the speaker says with the intention that a specific person loves the listener, someone has a specific reading. In fact, sentence (43a) also permits a non-specific interpretation of someone. For example, if the speaker implies that 'there is a person who loves you' to comfort a friend who was in trouble, the quantifier someone does not refer to a particular individual. What is notable is the English quantifier someone can be interpreted in two ways whether it has a specific form such as partitive NPs or not.

In Turkish, there are two forms of determiners that mean 'some': birkaç and bazi. They are distinctive with respect to specificity. While birkaç can be either specific or non-specific, bazt is always specific (Enç 1991). In both languages (i.e., English and Turkish), the quantifier has the potential of being interpreted as either specific or nonspecific even though their morphological realizations are different in each context. The Korean existential quantifier nwukwunka makes no difference; it has a duality in interpretations. It can be non-specific or specific in declaratives such as (43b). On the other hand, nwukwunka prefers to have a non-specific reading in interrrogative sentences as observed in the experiment.

If I classify nwukwuna 'everyone' and nwukwunka 'someone' as a group such as 'strong intervener' with the reason being that they favor non-specific understanding in wh-questions, the classification may not be able to extend to their corresponding quantifiers in other languages. Hence, it may be unnecessary to make a strict separation between strong quantifiers and weak quantifiers within one language. More important is to see how a quantifier can be interpreted in what circumstances and find a unifying property beyond the parameters of languages.

\subsection{Other interveners}

In the literature, focusing elements like only, even, and also, negation, NPIs (Negative Polarity Items) have been observed to serve as offending elements in most 
languages while there have been substantial crosslinguistic variations in a set of quantificational interveners. This section will discuss briefly how interveners other than quantifiers can be analyzed from a new perspective presented in this paper.

Let us examine representative examples of focus-involved intervention effects.

$$
\begin{aligned}
& \text { a. }{ }^{*} \text { Minswu-man } / \sqrt{ } \text { Minswu-ka nwukwu-lul po-ass-ni? } \\
& \text { Minswu-only/Minswu-Nom who-Acc see-Past-Q } \\
& \text { 'Who did *only Minswu } / \sqrt{ } \text { Minswu see?' } \\
& \text { b. *Amwuto mwues-ul ilk-ci anh-ass-ni? } \\
& \text { anyone what-Acc read-CHI not-do-Past-Q } \\
& \text { 'What did no one read?' }
\end{aligned}
$$

(Beck \& Kim, 1997)

In (44a), considering that using Minswu-ka 'Minsu-Nom' instead of Minswu-man leads to grammaticality, 'only' is accountable for the intervention effect. To obtain the successful interpretation of the question, we have to presuppose that there is someone that non-Minswu's didn't see but Minswu saw. In other words, the question is about the set of people which were not seen by non-Minswu's. That kind of interpretation is not obtainable, however. Accordingly, my current mechanism explains about the unacceptability of (44a) like this: 'Minswu-only' itself cannot be a specific referent although 'Minswu' refers to a specific individual, and thus the non-specificity of the focusing item leads to the illegitimacy of the structure. The example in (44b) shows that amwuto 'anyone', an NPI22), blocks the interpretation of the wh-phrase. Since amwuto cannot serve as a specific subject in a wh-question, the sentence is uninterpretable. As such, the infelicity of the above examples ${ }^{23)}$ is well understood by means of the notion of 'epistemic specificity'. Not only intervening quantifiers but focusing elements (consistently strong interveners) are connected to non-specific interpretations. When a wh-question requires some information about an element, the element must have a specific referent whether it is an entity or a group. Otherwise, intervention effects are inevitable. A simple explanation is the most economical, which is a central principle of the Minimalist Program.

22) It is also depicted as a 'focused item' in that it is to 'also' marked.

23) Related to these examples, it is obvious that focus interpretation is closely linked to the intervention effect (see Beck, 2006). However, we maintain that 'epistemic non-specificity' is at the core of intervention phenomena since there are cases where an intervention arises even though a quantifier is not associated with focus. 


\section{Conclusions}

This paper focuses on 'quantifiers and their intervention effects' since there have been very little research directly investigating the topic. We observed in the experiment that the 'epistemically non-specific' state of a quantificational element, not a certain quantifier, is responsible for its intervening character. In addition to this, what is crucial in evaluating the intervention effect in a wh-question is that how the addressee perceives a quantifier (a potential intervener) is more significant than how the speaker does. Whether a potential intervener serves as an intervener in a wh-question relies on how the addressee evaluates the truth of the proposition about which the question asks. The addressee's perceiving a quantificational subject as non-specific is a key factor in inducing an intervention effect. On the other hand, the intervening status of a quantifier can be 'off' when the addressee recognizes it as a particular individual (or group) by context or some of his/her knowledge. In a nutshell, an identical quantifier may or may not serve as an intervener.

Thus, the rigid distinction of a set of interveners and that of non-interveners is problematic and we should note that the intervening status of a quantifier is changeable instead of being fixed. This novel perspective has some advantages as follows. First, it accounts for why there have been disputes over grammaticality judgments among native speakers. No studies have taken seriously into account the effect of a context and distinguished the speaker's cognition from the addressee's in intervention circumstances. Second, it overcomes the limitations of previous pure syntactic, semantic, or information structure-based analyses that cannot elucidate why all scrambled versions do not always yield amelioration effects and why the D-linkedness of a wh-in situ (an intervenee) is not the decisive factor in cancelling intervention effects; it suggests that we can properly understand the intervention phenomenon at the interface of syntax and semantics/pragmatics. Third, this article elaborates on the concept of 'specificity', thereby illuminating why the notion of epistemic specificty is most associated with the intervention effect. Lastly, it provides a more convincing and unified account of intervention-related data. The argument that the essential property of interveners is 'epistemic non-specificity' extends to other interveners such as focusing items and NPIs. (How it can apply to other languages is left for future research.) 


\section{References}

Beck, S. (1996). Quantified structures as barriers for LF movement. Natural Language Semantics, $4(1), 1-56$.

Beck, S. (2006). Intervention effects follow form focus interpretation. Natural Language Semantics, 14, 1-56.

Beck, S. \& Kim, S. -S. (1997). On wh-and operator scope in Korean. Journal of East Asian Linguistics, 6, 339-384.

Choi, Y. -S. (2007). Intervention effect in Korean wh-questions: Indefinite and beyond. Lingua, 117, 2055-2076.

Chomsky, N. (1973). Conditions on transformations. In S. Anderson, \& P. Kiparsky (Eds.), A Festschrift for Morri Halle(pp. 232-286). New York: Holt, Reinhart and Winston.

Diesing, M. (1992). Indefinites. Cambridge: MT Press.

Enç, M. (1991). The semantics of specificity. Linguistic Inquiry, 1-25.

Erlewine, M. Y., \& Kotek, H. (2017). Intervention tracks scope-rigidity in Japanese. Proceedings of LENLS, 14.

Farkas, D. F. (1994). Specificity and scope. In L. Nash, \& G. Tsoulas (Eds.), Langues et Grammaire(Vol. 1).

Farkas, D. F. (2002). Specificity distinctions. Journal of Semantics, 19(3), 213-243.

Fodor, J. D., \& Sag, I. A. (1982). Referential and quantificational indefinites. Linguistics and Philosophy, 5(3), 355-398.

Ha, I. (2004). Specificity and intervention effects in Korean. LSO working papers in linguistics (Vol. 4, pp. 21-31). Madison, Wisconsin: University of Wisconsin-Madison Department of Linguistics. Proceedings of WIGL.

Hoji, H. (1985). Logical form constraints and configurational structures in Japanese (Doctoral dissertation). University of Washington.

Kim, J. (2018). Intervention effect, scope, and type-shifting. Linguistic Research, 35(2), 305-335.

Kim, S. -S. (2002). Questions, focus, and intervention effects. In Kuno \& Susumu (Eds.) Harvard studies in Korean linguistics (Vol. 6, pp. 520-533).

Mogi, T. (2000). Toritate-shi-no kaisosei-ni tsuite [on the layeredness of focus particles]. In Proceedings of the Fall 2000 meeting of the Society for Japanese Linguistics (pp. 54-61).

Moon, G. S., Wee, H. K., Kim, S. W., Park, M. K., Yim, C. K., \& Kim, C. M. (2009). Brain responses to intervention effects in Korean. Korean Journal of Linguistics, 34(3), 529-551.

Pesetsky, D. (1987). Wh-in-situ: Movement and unselective binding. In E. Reuland, \& A. ter Meulen (Eds.), The representation of (in)definiteness (pp. 98-129). Cambridge, MA: MT Press. Luigi, R. (1990). Relativized minimality. Cambridge: MIT Press.

Luigi, R. (2013). Locality. Lingua 130, 169-186.

Tenny, C. L. (2006). Evidentiality, experiencers, and the syntax of sentience in Japanese. Journal of East Asian Linguistics, 15(3), 245-288.

Tomioka, S. (2007). Pragmatics of LF intervention effects: Wh-interrogatives in Japanese and Korean. Journal of Pragmatics 39, 1570-1590. 
Min Jegal

Ph.D.

Department of English Language and Literature

Kyungpook National Univerisity

80 Daehakro, Bukgu, Daegu 41566, Korea

E-mail: 177117now@gmail.com

Received: July 1, 2021

Revised version received: August 9, 2021

Accepted: September 17, 2021

\section{Appendix: Target Sentences Included in the Survey}

For reasons of space, I use Q1,Q2,Q3,Q4, and Q5 for nwukwuna 'everyone' nwukwunka 'someone' sey myeng 'three CL' seymyeng isang 'more than three' tasesmyeng miman 'fewer than five', in order.

\section{Context A.}

1. Sentence type: Basic

$\mathrm{Q} 1 / \mathrm{Q} 2 / \mathrm{Q} 3 / \mathrm{Q} 4 / \mathrm{Q} 5-\mathrm{i} / \mathrm{ka}$ mwues-ul kacyew-ass-e? Q1/Q2/Q3/Q4/Q5-Nom what-Acc bring-past-Q

'What did everyone/someone/four people/more than three/fewer than five bring?'

2. Sentence type: D-linked (wh)

$\mathrm{Q} 1 / \mathrm{Q} 2 / \mathrm{Q} 3 / \mathrm{Q} 4 / \mathrm{Q} 5-\mathrm{i} / \mathrm{ka}$ chwuchen umsik moklok cwungey mwues-ul Q1/Q2/Q3/Q4/Q5-Nom recommended food list among what-Acc kacyew-ass-e?

bring-past-Q

'Which food in the recommended food list did Q1/Q2/Q3/Q4/Q5 bring?'

3. Sentence type: Scrambled

Mwuesul Q1/Q2/Q3/Q4/Q5-i/ka kacyew-ass-e?

What-Acc Q1/Q2/Q3/Q4/Q5-Nom bring-past-Q

'What did Q1/Q2/Q3/Q4/Q5 bring?' 
4. Sentence type: Embedded

Ne-nun [ Q1/Q2/Q3/Q4/Q5-i/ka mwues-ul kacyew-ass-ta-ko] you-Top. Q1/Q2/Q3/Q4/Q5-Nom what-Acc bring-past-dec.-comp sayngkakha-ni?

think-Q

'What do you think that Q1/Q2/Q3/Q4/Q5 brought?'

\section{Context B.}

1. Sentence type: Basic

Q1/Q2/Q3/Q4/Q5-i/ka nwukwu-lul conkyengha-ni $\mathrm{Q} 1 / \mathrm{Q} 2 / \mathrm{Q} 3 / \mathrm{Q} 4 / \mathrm{Q} 5-\mathrm{Nom}$ who-Acc respect-Q 'who does/do everyone/someone/two people/more than five/fewer than seven respect?'

2. Sentence type: D-linked (wh)

Q1/Q2/Q3/Q4/Q5-i 7in-uy wiin-cwung enu inmwul-ul $\mathrm{Q} 1 / \mathrm{Q} 2 / \mathrm{Q} 3 / \mathrm{Q} 4 / \mathrm{Q} 5-\mathrm{Nom}$ 7-Gen great men-among which person-Acc conkyengha-ni?

respect-Q

'Which person among 7 great men do Q1/Q2/Q3/Q4/Q5 respect?'

3. Sentence type: Scrambled

Nwukwulul Q1/Q2/Q3/Q4/Q5-i/ka conkyengha-ni

Who-Acc Q1/Q2/Q3/Q4/Q5-Nom respect-Q

'Who does/do Q1/Q2/Q3/Q4/Q5 respect?'

4. Sentence type: Embedded

Ne-nun [Q1/Q2/Q3/Q4/Q5-i/ka nwukwu-lul conkyenghan-ta-ko] you-Top Q1/Q2/Q3/Q4/Q5-Nom who-Acc respect-dec.-comp sayngkakha-ni?

think-Q

'What do you think that Q1/Q2/Q3/Q4/Q5 respect?' 